DOI https://doi.org/10.18551/rjoas.2017-11.20

\title{
THE IMPLICATION OF PURCHASE INTENTION: ANALYSIS OF PERCEIVED USEFULNESS, PERCEIVED ENJOYMENT, TECHNICALITY AND PERCEIVED PRICE TOWARDS PERCEIVED VALUE
}

\author{
Wreksa Rahadian Pandega \\ Multimedia Nusantara University, Tangerang, Indonesia \\ E-mail: rahadianpandega@gmail.com
}

\begin{abstract}
The purpose of this study is to obtain result of analysis of the effect of Perceived Usefulness towards Perceived Value, Perceived Enjoyment towards Perceived Value, Technicality towards Perceived Value, Perceived Price towards Perceived Value, and Perceived Value towards Purchase Intention. This study is a descriptive and exploratory research. The descriptive study is a kind of research which purpose is to describe or figure out the characteristics and nature of market and consumer behavior. On the other hand, the exploratory study is a kind of research which purpose is to explore or collect any deeper thoughts about a problem. The research design used is survey in which sampling unit is observed using a questionnaire. The unit samplings used in this study are men and women who once access iTunes Store, know Kotak Band, and never once purchase Kotak's songs ("Never Dies" album). The result of the analysis using Structural Equation Modeling (SEM) shows that the data of this study have goodness of fit with the proposed research model and the measurement model of overall indicators has valid criteria and reliability or consistency of good measurement. Regarding to the result of the structural model, it can be concluded that Perceived Usefulness gives positive effect towards Perceived Value, and Perceived Enjoyment gives positive effect towards Perceived Value. On the other hand, other variables give negative effect.
\end{abstract}

\section{KEY WORDS}

Purchase intention, perceived usefulness, perceived enjoyment, technicality, perceived price.

The development of internet use in business world has been wider. Because of the development of technology, the use of internet to help business activities, small-medium enterprises increase. Then, it means that every company should place itself to fulfill people's needs which are getting demanding (Gotlieb et al, 1994). Not only do they changing and improvement to their product or service offered, but also they need to change their marketing strategy (Chaffey, 2007). It is done for many reasons, but commonly, the changing of marketing strategy is done by a company to create an image or alter look among the consumers (Chellappa and Sin, 2005). Therefore, they expect that their product can be more acceptable for people and can reach wider market and affect their rating sales and company's profit (Keaveney, 1995).

In Indonesia, the e-commerce service providers are getting more. For instance, Kaskus established in 1999 was only a forum for internet users, but nowadays it becomes one of the largest e-commerce service providers in Indonesia. The users are about 5 million people and its transaction has reached up to 575 billion rupiah. Besides Kaskus, other e-commerce service providers in Indonesia are Toko Bagus, Berniaga, Lazada, Bhinneka, and many more. The e-commerce markets in Indonesia are nowadays also occupied by some banks providing online commerce websites, such as Citibank (Belibarang.com), BNI (Blandja.com), and Mandiri (Tokone.com). Moreover, Limited Liability Company of Post Office which is declining does a new alternative by launching Plaza Pos Indonesia in 2012, and now it is developing. It uses the distribution network to 3.217 sub-unit offices and international post network to more than 200 countries. Its purchasing system can be offline (coming to the post office directly) or online. 
The creative industry of subsector music is a creative activity relating to the creation or composition, music show, reproduction, and distribution of voice recording. Music, in context of creative industry development, does not only a kind of expressing sounds which basis is in a form of melody, rhythm, and harmony with supporting factor in a form of idea, characteristics, and timbre, but it also an output which can be enjoyed by many people and give benefits of economy, social, and culture. Music in its development is one of creative industry emphasizing more on the development of music industry which is expected to be able to give additional economic value for people who are involved in it and give life quality for its connoisseurs.

iTunes is the benchmark of the pride and success of the digital music distribution. The minimum knowledge about digital distribution is linear with the performance of music streaming business in Indonesia. The music industry, like other industries, changes because of the development of technology (Davis et al, 1992). One of the factors causing great change is iTunes. Its existence in Indonesia in 2012 has changed Indonesian music industry. Based on the data recorded in 2014, the sales rating of music download in iTunes stores is controlled by the five-greatest-market Pan Asia, i.e. Philippine, Indonesia, India, Singapore, and Thailand.

On March 18, 2014, one of popular rock bands in Indonesia named "KOTAK" had released their album entitled "Never Dies" via iTunes. They packaged their song in a new format and the process of "Never Dies" album making was only a month. After "Never Dies" was officially released via iTunes, Kotak Band has been considered well in Indonesian music industry as it can be proven by the achievement of Kotak Band which became the first Indonesian artist receiving page artist in the world digital music canal (www.xposeindonesia.com). Kotak Band then realized that internet users are getting more. Besides, many media helped every band to promote and sell their masterpiece. iTunes is one of the media chosen by Kotak to promote and sell their songs in the "Never Dies" album (www.xposeindonesia.com).

One of members of Kotak chose iTunes because it was one of a promotion strategy of "Never Dies" album sales which made their fans easier to purchase the album without going to a store which was actually time consuming. The management of Kotak Band reveals that by selling Kotak's album in iTunes, they can control their selling album; besides, their fans do not have to spend money to purchase one album, but they only have to purchase songs they want. They think that iTunes is a benefit for them because by using iTunes, they hope their fans can get more benefits and comfort in purchasing Kotak's songs in iTunes than purchasing the real album.

Perceived usefulness is defined as how far someone believes that purchasing via online will increase his or her performance (Davis, 1989). It is done by Kotak to make Kotak's song purchasing in online music store easier. On the other hand, perceived enjoyment is one of the factors influencing Kotak's fans to purchase through iTunes. As it is stated by Hopkinson and Pujari (1999), perceived enjoyment is one of the factors influencing someone to do something. Perceived usefulness and perceived enjoyment are a part of benefit which can influence consumers to do something.

By the existence of Kotak's songs in iTunes, it can make their fans easier to purchase their songs without spending much time and money to purchase Kotak's songs through iTunes. If they purchase Kotak's songs in offline store, they need more effort than purchasing them through iTunes. It refers to the definition of technicality or nonmonetary sacrifice as it is revealed by Zeithaml (1998) that consumers will spend much time and effort in a product or service and it can influence the value perception of a product or service. In terms of price, purchasing songs in iTunes is cheaper than purchasing CD in offline stores. Kotak's fans can purchase any songs they like. In this case, it refers to the perceived price revealed by Kotler and Amstrong (2010) that price is amount of money spent by consumers to get a product or service.

The purpose of this study is to obtain the result of analysis of the effect of Perceived Usefulness towards Perceived Value, Perceived Enjoyment towards Perceived Value, 
Technicality towards Perceived Value, Perceived Price towards Perceived Value, and Perceived Value towards Purchase Intention.

\section{METHODS OF RESEARCH}

This study is a descriptive and exploratory study. The descriptive study is a study which purpose is to describe or figure out any characteristics and nature of market and consumer behavior. Besides, the exploratory study is to explore or collect any deeper thoughts about particular problem. The research designed used in this study is survey in which observing the sampling unit using a questionnaire. The questionnaire was designed orderly and structurally, and then it was distributed to the samples of a population in order to obtain specific information from the respondents (Malhotra, 2012). In general, this study will observe any factors influencing purchase intention towards Kotak's songs ("Never Dies" album) in iTunes Store. The variables of tis study are perceived usefulness, perceived enjoyment, technicality, perceived price, perceived value, and purchase intention.

The unit of the samples used in this study were men and women who once accessed iTunes Stores and know Kotak and never once purchased Kotak's songs ("Never Dies" album). The defining of the number of samples was based on a theory by Hair et al. (2010) stating that the number of samples defined fit the number of question items used in the questionnaire by assuming $\mathrm{n} \times 5$ observation up to $\mathrm{n} \times 10$ observation. However, in this study, the researcher uses $n \times 7$ with 22 question items used to measure 6 variables; thus, the number of respondents used was 22 question items multiplied by 7 meaning that there are 154 respondents.

\section{RESULTS AND DISCUSSION}

The Result of Structural Equation Model (SEM) Data Analysis. To analyze SEM data in this study, the researcher used software named Lisrel Version 8.8 Program. This program helped the researcher test the correlation among variables easier. The result of the calculation of SEM using Lisrel Version 8.8 can be seen in the appendix. In SEM analysis, the evaluation towards the level of goodness of fit of the data with the model is done in some stages, such as overall goodness of fit model, measurement model testing, and structural model testing (Wijayanto, 2008).

The Result of Overall Goodness of Fit Model Analysis. The first step is testing the overall goodness of fit which purpose is to generally evaluate the level of Goodness of Fit (GOF) between the data and the research model (Wijayanto, 2008). This is the result of overall goodness of fit test using Lisrel version 8.8.

Table 1. The Result of Overall Goodness of Fit Analysis

\begin{tabular}{|c|c|c|}
\hline Goodness of Fit (GOF) Index & Level of Acceptable Goodness of Fit & Category \\
\hline \multicolumn{3}{|c|}{ Absolute Fit Measure } \\
\hline Statistik Chi - Square $\left(X^{2}\right) P$ & $211.98(p=0.24)$ & Good Fit \\
\hline Non-Centraly Parameter (NCP) & $85.82(46.03 ; 133.61)$ & Good Fit \\
\hline Goodness-of-Fit Index (GFI) & 0.89 & Marginal Fit \\
\hline Standardized Root Mean Square Residual (SRMR) & 0.059 & Good Fit \\
\hline Root Mean Square Error of Approximation (RMSEA) & 0.021 & Good Fit \\
\hline Expected Cross Validation Index (ECVI) & $\begin{array}{l}M=2.10 \\
S=3.31 \\
I=14.23\end{array}$ & Good Fit \\
\hline \multicolumn{3}{|c|}{ Incremental Fit Measure } \\
\hline Non-Normed Fit Index (NNFI) & 0.99 & Good Fit \\
\hline Normed Fit Index (NFI) & 0.90 & Good Fit \\
\hline \multicolumn{3}{|c|}{ Incremental Fit Measure } \\
\hline Adjusted Goodness-of-Fit Index (AGFI) & 0.86 & Marginal fit \\
\hline Relative Fit Index (RFI) & 0.88 & Marginal fit \\
\hline Incremental Fit Index (IFI) & 0.99 & Good Fit \\
\hline Comparative Fit Index (CFI) & 0.99 & Good Fit \\
\hline
\end{tabular}




\begin{tabular}{|c|c|c|}
\hline \multicolumn{3}{|c|}{ Parsimonius Fit Measure } \\
\hline Parsimonius Goodness of Fit Index PGFI) & 0.70 & Good Fit \\
\hline & $\mathrm{M}=321.98$ & Good Fit \\
\hline Akaike Information Criterion (AIC) & $\mathrm{S}=506.00$ \\
& $\mathrm{I}=2177.71$ & $\mathrm{M}=544.01$ \\
Consistent Akaike Information Criterion (CAIC) & $\begin{array}{c}\mathrm{S}=1527.35 \\
\mathrm{I}=2266.52\end{array}$ & Good Fit \\
\hline
\end{tabular}

$\mathrm{M}^{*}=$ Model; $\mathrm{S}^{*}=$ Saturated; $\mathrm{I}^{*}=$ Independence

Based on the result of the providing data in the table, it can be seen that there are $12 \mathrm{GOF}$ Indices showing good fit and 3 Indices showing marginal fit. Therefore, it can be concluded that the overall goodness of fit is good, so this study can be continued.

\subsection{The Result of Structural Model Analysis}

The purpose of having structural model is to know the correlation among variables which fits the research model. Based on SEM calculation using Lisrel Version 8.80, the equation of structural model research is as the following:

$$
\eta 1=0.29^{*} \xi 1+0.27^{*} \xi 2-0.36^{*} \xi 3-0.21^{*} \xi 4, \text { Errorvar. }=0.68, R^{2}=0.32
$$

Where:
$\xi 1($ ksi 1$)=$ Perceived Usefulness;
$\xi 2($ ksi 2$)=$ Perceived Enjoyment;
$\xi 3$ (ksi 3) = Technicality;
$\xi 4$ (ksi 4) = Perceived Price;
$\eta 1$ (eta 1$)=$ Perceived Value;
ฤ2 (eta 2) = Purchase Intention.

Based on this study, when the criteria of structural model testing are going to be defined, the comparison between t-value and t-table should be made as it is shown in the path diagram figure in the following.

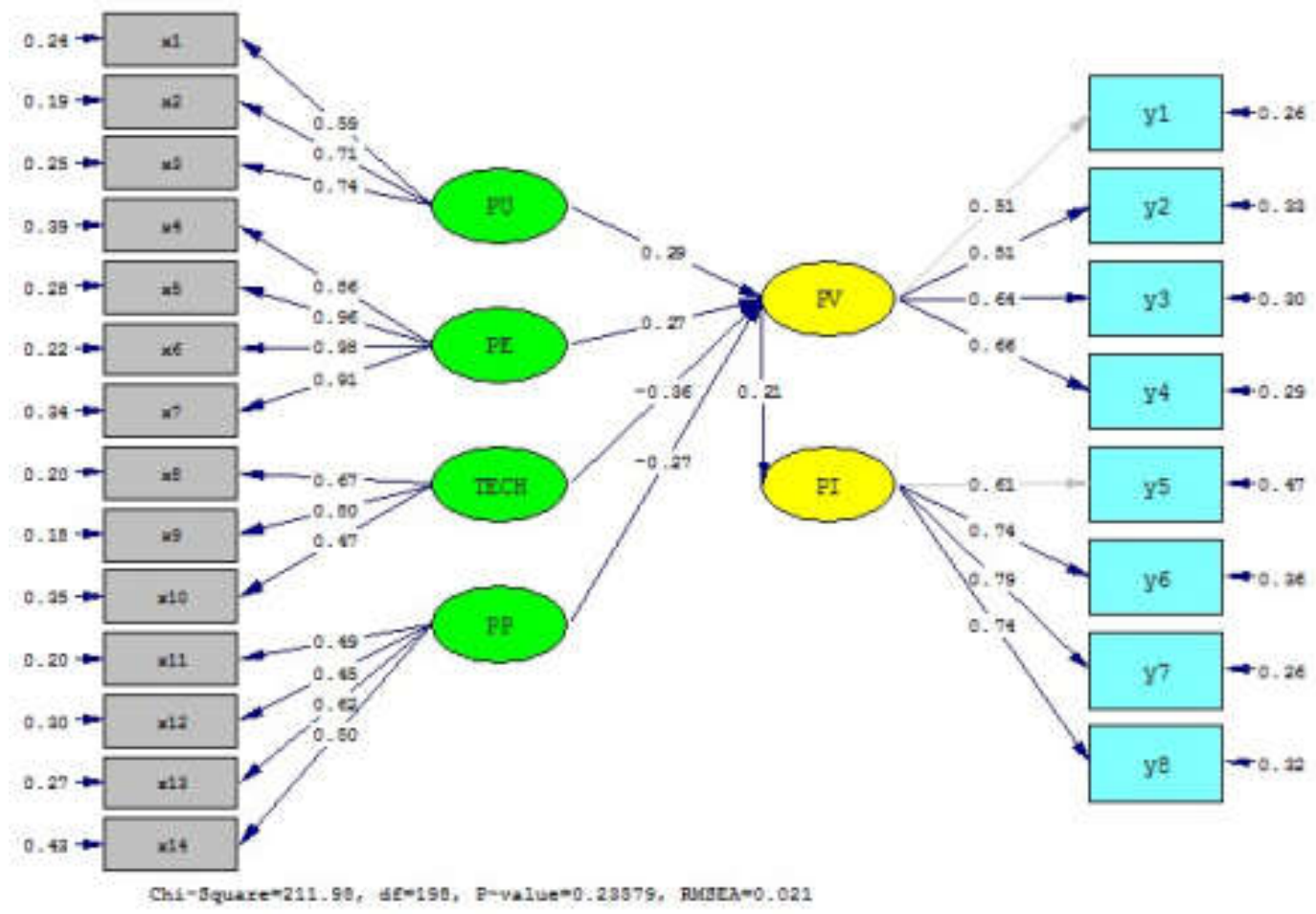

Figure 1 - Path Diagram Estimates 


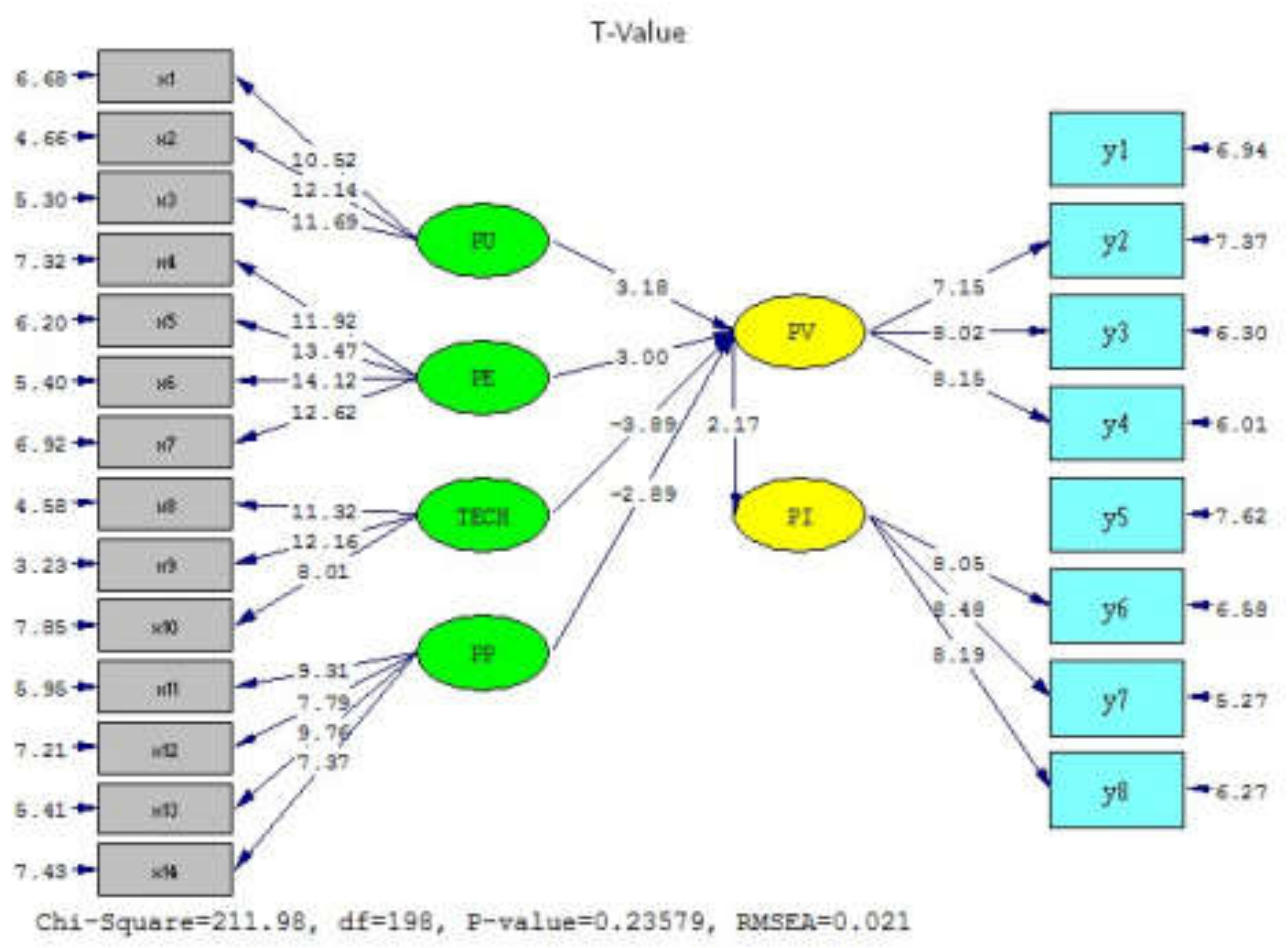

Figure 2 - Path Diagram T-Value

Table 2 - The Result of Structural Model Analysis

\begin{tabular}{|c|l|c|c|c|c|}
\hline $\mathrm{H}$ & \multicolumn{1}{|c|}{ Path } & Estimation & T-Value & T-Tabel & Conclusion \\
\hline 1 & Perceived Usefulness $\rightarrow$ Perceived Value & 0.29 & 3.18 & 1.96 & Data support H1 \\
\hline 2 & Perceived Enjoyment $\rightarrow$ Perceived Value & 0.27 & 3.00 & 1.96 & Data support H2 \\
\hline 3 & Technicality $\rightarrow$ Perceived Value & -0.36 & -3.89 & 1.96 & Data support H3 \\
\hline 4 & Perceived Price $\rightarrow$ Perceived Value & -0.27 & -2.89 & 1.96 & Data support H4 \\
\hline 5 & Perceived Value $\rightarrow$ Purchase Intention & 0.21 & 2.17 & 1.96 & Data support H5 \\
\hline
\end{tabular}

Hypothesis 1. The first hypothesis is to measure the effect of Perceived Usefulness towards Perceived Value. The research hypothesis $(\mathrm{H} 1)$ is as the following. $\mathrm{H} 1$ : Perceived Usefulness gives positive effect towards Perceived Value. Based on the result of structural model calculation for the first hypothesis, it is found that $t$-value is 3.18 which is greater than $\mathrm{t}$-table. Therefore, significantly, the data of this research support the statement that there is a positive effect between Perceived Usefulness and Perceived Value.

Hypothesis 2. The second hypothesis is to measure the effect of Perceived Enjoyment towards Perceived Value. The research hypothesis $(\mathrm{H} 2)$ is as the following. H2: Perceived Enjoyment gives positive effect towards Perceived Value. Based on the result of structural model calculation for the second hypothesis, it is found that t-value is 3.00 which is greater than t-table. Therefore, significantly, the data of this research support the statement that there is a positive effect between Perceived Enjoyment and Perceived Value.

Hypothesis 3. The third hypothesis is to measure the effect of Technicality towards Perceived Value. The research hypothesis $(\mathrm{H} 3)$ is as the following. H3: Technicality gives negative effect towards Perceived Value. Based on the result of structural model calculation for the third hypothesis, it is found that $t$-value is -3.89 which is lower than $t$-table. Therefore, significantly, the data of this research support the statement that there is a negative effect between Technicality and Perceived Value.

Hypothesis 4. The fourth hypothesis is to measure the effect of Perceived Price towards Perceived Value. The research hypothesis $(\mathrm{H} 4)$ is as the following. H4: Perceived Price gives negative effect towards Perceived Value. Based on the result of structural model calculation for the fourth hypothesis, it is found that $t$-value is -2.89 which is lower than $t-$ 
table. Therefore, significantly, the data of this research support the statement that there is a negative effect between Perceived Price and Perceived Value.

Hypothesis 5. The fifth hypothesis is to measure the effect of Perceived Value towards Purchase Intention. The research hypothesis (H5) is as the following. H5: Perceived Value gives negative effect towards Purchase Intention. Based on the result of structural model calculation for the fifth hypothesis, it is found that t-value is 2.17 which is greater than t-table. Therefore, significantly, the data of this research support the statement that there is a positive effect between Perceived Value and Purchase Intention.

\section{DISCUSSION OF RESULTS}

From the result of measuring model analysis showing that all variables have fulfilled the criteria of validity and reliability testing. Moreover, all of the proposed hypotheses have significant result. These are the result of discussion towards the structural model testing of each variable.

\section{Testing}

The Result of the Effect of Perceived Usefulness towards Perceived Value

The result of structural model testing shows that there is an effect between Perceived Usefulness and Perceived Value. It is in line with the result of a study conducted by Lee \& Park (2006) stating that the level of value will increase when consumers get benefits of using online store. Moreover, Fenech (1998) states that the power of determination of consumers for a value is based on the use obtained by every consumer. Van der Heijden (2004) says that Perceived Usefulness positively affects the Perceived Value.

\section{Testing}

The Result of the Effect of Perceived Enjoyment towards Perceived Value

The result of structural model testing shows that there is an effect between Perceived Usefulness and Perceived Value. It is in line with the result of a study stating that how far the consumers believe that enjoyment can be derived when listening to online music and it might be encouraged by satisfaction factor when they do the transaction in an online store (Chu and Lu, 2007). It shows that Perceived Enjoyment positively affects the Perceived Value.

The Result of the Effect of Technicality towards Perceived Value Testing

The result of structural model testing shows that there is an effect between Technicality and Perceived Value. It is supported by the result of a study conducted by Atkinson \& Kydd (1997) stating that technicality is the degree of consumers' belief that listening online music is an effort. Therefore, the online consumers can see that they can decrease effort, decrease sacrifice, and increase the target value they want. Kim et al. (2007) states that the technique of online content service which is great can increase consumers in terms of physical and psychology. As a result, it will give negative contribution towards the Perceived Value. In other words, technicality affects negatively towards Perceived Value.

The Result of the Effect of Perceived Price towards Perceived Value Testing

The result of structural model testing shows that there is an effect between Perceived Price and Perceived Value. The result is in line with the result of a study conducted by Winer (1986) stating that Perceived Price affects negatively towards Perceived Value.

The Result of the Effect of Perceived Value towards Purchase Intention Testing

The result of structural model testing shows that there is an effect between Perceived Value and Purchase Intention. The result is in line with the result of a study conducted by Van der Heijden (2004) stating that Perceived Value affects positively towards Purchase Intention.

\section{Managerial Implication}

Based on the result of SEM above, it has been proven that there is an effect between Perceived Usefulness, Perceived Enjoyment, Technicality, and Perceived Price towards Purchased Intention through Perceived Value. The results of this study should be able to give evaluation for Kotak Band in increasing consumers' need to do Purchase Intention. Besides, it should be supported by the increase of Perceived Usefulness, Perceived Enjoyment, Technicality, and Perceived Price through Perceived Value. In this case, there 
are some approaches which can be used to increase Perceived Usefulness so that Perceived Value can increase.

To increase value towards a brand, Kotak Band should increase the function of use so that consumers get good value towards Kotak Band. The finding obtained by the researcher is that Kotak Band thinks that consumers need practicality in accessing Kotak's songs, especially songs in "Never Dies" album in iTunes Store. Consumers also want to get its easiness if it is compared to purchasing the Kotak's CD in offline stores. Through iTunes Store, consumers can also know any update information about Kotak without watching TV or listening to a radio.

Besides, there are some approaches which can be used to increase Perceived Enjoyment so that Perceived Value can increase. Basically, one of the factors in which it can make consumers happy for good value of a brand is when they feel happy for purchasing it. The finding obtained by the researcher is that consumers are happy because consumers and also Kotak's fans can listen to Kotak's song teaser in iTunes Store. Through Kotak's song teaser in iTunes Store, consumers can judge Kotak's songs.

Moreover, there are some approaches which can be used to decrease Technicality so that Perceived Value can increase. Kotak Band chose iTunes Store to release songs of the latest "Never Dies" album because iTunes Store is considered to being able to access Kotak's songs easier. The finding obtained by the researcher is that the value obtained by consumers will decrease if it is difficult and time consuming for them to play teaser. If it occurs, consumers will think that there is no difference between online purchasing and purchasing Kotak's CD because it is time consuming to obtain Kotak's songs, especially for those who want to listen to Kotak's song teaser so that there is a value obtained after listening to Kotak's song teaser. Because of the reason, the researcher suggest Kotak Band to socialize the use of iTunes Store can make consumers play Kotak's song teaser easily so that they get a value, and then decide whether to purchase Kotak's songs or not.

Moreover, there are some approaches which can be used to decrease Perceived Price so that Perceived Value can increase. Price is one of the factors for the consumers to have certain value of a brand until they decide to purchase or not. The finding obtained by the researcher is that the latest price of Kotak's songs is cheaper than its CD. However, the process of transaction in iTunes Store should use credit card. Those who do not have credit card think that there is no difference between the price offered by iTunes and the price of purchasing $C D$ because it needs more money to register a credit card since most of the respondents seen by the researcher have no regular salary. Therefore, the researcher suggests Kotak Band to provide and sell iTunes Gift Card for consumers who want to purchase Kotak's songs in iTunes so that the value towards Kotak Band is good for consumers.

In addition, there are some approaches which can be used to increase Perceived Value so that Perceived Intention can increase. Consumers will purchase a brand if they choose good response for a brand. The finding obtained by the researcher shows that whenever consumers feel good towards Kotak's songs in iTunes Store, they will predict and be willingly to purchase Kotak's songs in "Never Dies" album in iTunes Store.

Consumers will not purchase the songs if they have no good judgment towards Kotak's songs, especially in "Never Dies" album. Therefore, the researcher suggests Kotak Band to give things which encourage consumers to judge Kotak Band well so that they want and are willing to purchase Kotak's songs, especially in "Never Dies" album in iTunes Store.

\section{CONCLUSION}

Before conducting this study, the researcher administered a pretest by distributing questionnaires to 30 respondents which were distributed based on the criteria set by the researcher. The result of the questionnaires distributed to 30 respondents is respondents who wanted to purchase Kotak's songs ("Never Dies" album) in iTunes Store. Based on the interview result, the researcher deepens the study about Purchase Intention on Kotak's songs ("Never Dies" album). 
The result of data analysis using Structural Equation Modeling (SEM) shows that the data of this study fit the proposed research model and all indicators of the measuring research model have valid criteria and reliability or consistency of good measurement. The results of the structural model can be concluded as:

- Perceived Usefulness gives positive effect towards Perceived Value;

- Perceived Enjoyment gives positive effect towards Perceived Value;

- Technicality gives negative effect towards Perceived Value;

- Perceived Price gives negative effect towards Perceived Value;

- Perceived Value gives positive effect towards Purchase Intention.

\section{REFERENCES}

1. Chaffey, D. (2007). E-business and E-commerce Management: Strategy, Implementation and Practice. Pearson Education.

2. Chellappa, R. K., \& Sin, R. G. (2005). Personalization versus privacy: An empirical examination of the online consumer's dilemma. Information technology and management, 6(2), 181-202.

3. Chu, C. W., \& Lu, H. P. (2007). Factors influencing online music purchase intention in Taiwan: An empirical study based on the value-intention framework. Internet Research, 17(2), 139-155.

4. Davis, F. D. (1989). Perceived usefulness, perceived ease of use, and user acceptance of information technology. MIS quarterly, 319-340.

5. Davis, F. D., Bagozzi, R. P., \& Warshaw, P. R. (1992). Extrinsic and intrinsic motivation to use computers in the workplace. Journal of applied social psychology, 22(14), 11111132.

6. Gotlieb, J. B., Grewal, D., \& Brown, S. W. (1994). Consumer satisfaction and perceived quality: complementary or divergent constructs?. Journal of applied psychology, $79(6)$, 875.

7. Hair, J. F., Black, W. C., Babin, B. J., Anderson, R. E., \& Tatham, R. L. (1998). Multivariate data analysis (Vol. 5, No. 3, pp. 207-219). Upper Saddle River, NJ: Prentice hall.

8. Hopkinson, P (1999). The Chambers Dictionary (1993) "a consumer based assement. http://.marketing.co.id/pertumbuhan-e-commerce-indonesia-tercepat-di-dunia

9. Keaveney, S. M. (1995). Customer switching behavior in service industries: An exploratory study. The Journal of Marketing, 71-82.

10. Kotler, P., \& Armstrong, G. (2010). Principles of marketing. Pearson education.

11. Van der Heijden, H, (2004). "User Acceptance of Hedonic Information Systems", MIS Quarterly Vol. 28, No. 4, pp. $695-704$.

12. Xposeindonesia. 2014. "Band Kotak sadar akan pengguna internet semakin meningkat" $2014 \mathrm{http}: / / x p o s e i n d o n e s i a . c o m$

13. Zeithaml, V. A. (1988). Consumer perceptions of price, quality, and value: A mean send model and synthesis of evidence. Journal of Marketing, 52(3), 2-22. 